\title{
A PARTICIPAÇÃO DA MULHER NA POLÍTICA BRASILEIRA E A EFETIVIDADE DAS COTAS PARTIDÁRIAS
}

\author{
The participation of women in brazilian politcs and the effectiveness of the \\ party shares
}

\section{Crislayne Moura Leite} Wagner Wilson Deiró Gundim

Resumo: O presente estudo analisa a participação feminina na política brasileira sob o enfoque das cotas partidárias de gênero. Para tanto, percorre brevemente o cenário de lutas realizadas por mulheres que culminaram na conquista do sufrágio feminino no Brasil. Investiga desde o período colonial, quais foram as principais alterações legislativas referentes à atuação política das mulheres brasileiras e debate a real efetividade da legislação de cotas eleitorais de gênero. Nesse sentido, diante do fato de que as mulheres são maioria no eleitorado brasileiro, apontam-se as razões que impedem a maximização da participação feminina na política através do estudo sobre a estrutura interna da disputa eleitoral no Brasil e, além disso, perfaz uma análise comparada a partir das legislações da Argentina e da Bolívia a fim de verificar como esses países lidam com as cotas partidárias e como se dá sua aplicação.

Palavras-chave: Cotas de gênero. Representação feminina. Mulheres. Lei de cotas. Sufrágio feminino.

\begin{abstract}
The present study analyzes the participation of women in Brazilian politics under the focus of gender parity quotas. To do so, the scenario of struggles carried out by women culminating in the conquest of women's suffrage in Brazil it's analyzed. It investigates since the colonial periods, which were the main legislative changes regarding the political action of brazilian women and debates the real effectiveness of the legislation of electoral gender quotas. In this sense, given the fact that women are the majority in the Brazilian electorate, the reasons for maximizing women's participation in politics are pointed out through the study of the internal structure of the electoral dispute in Brazil and, moreover, a comparative analysis based on the legislation of Argentina and Bolivia in order to verify how these countries deal with partisan quotas and how they are applied.
\end{abstract}

Keywords: Gender quotas. Female Representation. Women. Law of Quotas. Female suffrage.

Artigo recebido em 15 jul. 2019 e aprovado em 16 ago. 2019. 


\section{Introdução}

Desde o período colonial, o Brasil comporta uma ausência da participação da mulher na política, seja no cumprimento do exercício do voto ou na candidatura a cargos públicos. O processo de participação feminina na política somente teve início na década de 1930, mais precisamente no governo Vargas, quando o código eleitoral de 1932 garantiu às mulheres o direito de votar, de serem votadas, o voto secreto e o alistamento eleitoral a partir de 18 anos. A conquista desses direitos políticos foi obtida a partir do surgimento de diversos movimentos organizados por mulheres em prol de causas relativas à emancipação feminina.

As mulheres foram um dos últimos contingentes sociais a obterem direitos políticos nas democracias contemporâneas. O direito ao voto feminino representou a primeira vitória na luta por cidadania política. Contudo, apesar de os terem conquistado, as mulheres ainda enfrentam grandes dificuldades em participar da disputa eleitoral e de se eleger a cargos públicos, principalmente do legislativo, espaço fundamental para dar centralidade e visibilidade de temas que têm se constituído como bandeiras da luta das mulheres e que precisam ser amplamente debatidos, problematizados e solucionados.

A constatação de que as mulheres são sub-representadas no espaço político aponta para a necessidade de adoção das ações afirmativas que proporcionem igualdade de gênero nesse âmbito. No caso do Brasil, foram adotadas as cotas partidárias de gênero que, desde a sua formatação, já sofreram diversas alterações na tentativa de introduzir mais mulheres ao debate público institucionalizado.

Essa ação afirmativa, portanto, é a problemática que se busca enfrentar no presente artigo: analisar a (in)efetividade das cotas partidárias, apontando quais as razões que impedem a maximização da representação feminina no cenário político brasileiro.

Para enfrentar o problema indigitado, o artigo é estruturado em três tópicos: no primeiro, aborda uma breve narrativa a respeito da luta das mulheres na busca pelo sufrágio feminino, para, na sequência (no segundo), indicar a real efetividade das cotas de gênero na promoção da igualdade política material. O terceiro e último tópico, por sua vez, faz uma análise de direito comparado sobre a aplicação das cotas eleitorais de gênero com a Argentina e a Bolívia, como objetos de estudo. 
A base de investigação científica foi composta pelos métodos dedutivos, indutivos e dialéticos, uma vez que as análises se pautam, respectivamente, na estrutura teórica, normativa interna e no direito comparado. A partir desse estudo, verificar-se-á se o método utilizado nesses países é realmente efetivo na implementação da representatividade feminina na política.

Assim, pretende-se, com o presente trabalho, contribuir para que o tema a respeito da participação das mulheres na política seja disseminado, de maneira que o conhecimento sobre a luta feminina por seus direitos não permita que mais mulheres se silenciem diante dos obstáculos que tentam lhes retirar a voz.

\section{A conquista do voto feminino no Brasil}

A desigualdade política de gênero permeia a História, tendo em vista a existência de uma separação entre as esferas pública e privada para mulheres. No sistema brasileiro, isso se originou devido à formação de uma sociedade patriarcal, na qual o homem era considerado o sujeito capaz e apto a atuar perante a sociedade, ao passo que a mulher limitava-se ao lar e ao cuidado dos filhos.

$\mathrm{Na}$ época do Brasil Império, durante a vigência da Constituição de 1824, que nada mencionava sobre a participação das mulheres na esfera política, o voto tornou-se um privilégio de uma pequena camada social, composta basicamente por homens maiores de vinte e cinco anos (SANTOS, 2009, p. 03).

A Proclamação da República, em 1889, não alterou as condições de participação política da população feminina. Em 1891, ocorreu a promulgação da primeira Constituição da República, a qual fortaleceu a exclusão, ao passo que manteve, como eleitores, apenas os cidadãos acima de vinte e um anos de idade, excluídos os analfabetos, soldados, mendigos e religiosos. $\mathrm{O}$ texto constitucional não fez menção explícita à participação das mulheres no cenário político.

Essa lacuna na norma constitucional respaldou o movimento feminino na busca pela conquista do direito ao voto, dando início a diversos pedidos de alistamentos, que sempre eram negados. A partir disso, em meados do século XIX surgiu a imprensa feminina, que foi o embrião do movimento das mulheres. Em 1852, foi fundado o primeiro jornal produzido para mulheres: O Jornal das Senhoras, que tinha como objetivo despertar a 
consciência feminina para que reivindicassem melhores condições educacionais e acesso ao mercado de trabalho. O jornal foi criado e dirigido pela argentina Juana Manso, jornalista e pioneira na expansão do feminismo (BITHIAH; RABAT, 2012, p. 34).

Assim, diante da privação dos direitos políticos das mulheres, em 1910, o movimento feminino fundou o Partido Republicano Feminino (PRF), liderado pela professora Leolinda de Figueiredo Daltro, eleita presidenta da agremiação (PINTO, 2003, p. 19). O PRF tinha como objetivo mobilizar as mulheres na luta pelo direito ao voto, mas, além disso, pugnava nos tribunais e na imprensa pelo bem do saneamento social, procurando extinguir toda e qualquer exploração relativa ao sexo feminino (SCHUMAHER, 2000).

A criação de um partido por mulheres que não possuíam direitos políticos foi muito relevante aos interesses políticos femininos. Em novembro de 1917, o partido promoveu uma passeata pelo sufrágio feminino com quase cem mulheres no centro do Rio de Janeiro, a qual foi definida, à época, como uma "pequena revolução", tendo em vista que aquele era um período em que as ruas eram interditadas para mulheres, que, nelas, somente deviam transitar por extrema necessidade e sempre acompanhadas (BUONICORE, 2009, p. 197-199).

Nesse período, surgiu uma personagem de grande importância para o movimento sufragista: Bertha Lutz, bióloga, advogada, pertencente à elite econômica, política e intelectual brasileira e fundadora da primeira escola de enfermeiras do Brasil. Bertha obteve condições de atuação que muitas mulheres não tiveram.

A bióloga e advogada criou a Liga para a Emancipação Intelectual da Mulher, uma espécie de grupo de estudos formado por um grupo de mulheres da elite burguesa da época. Ainda em 1922, organizou o primeiro Congresso Internacional Feminista no Rio de Janeiro e fundou a Federação Brasileira pelo Progresso Feminino (FBPF), com a principal atribuição de assegurar os direitos políticos e o direito à educação das mulheres (BUONICORE, 2009, p. 199).

A FBPF foi a mais importante e conhecida organização em defesa dos direitos da mulher no período. O grande marco da Fundação foi a luta contra as dificuldades de comunicação e o avanço na conquista do apoio na opinião pública em um período repleto de limitações às mulheres (PINTO, 2003, p. 24-25). 
No Brasil, a conquista do voto feminino começou a se concretizar em 1926, quando Washington Luís foi eleito presidente e incluiu em seu plano de governo a participação da mulher no processo eleitoral. A partir dessa manifestação favorável do Presidente, muitos projetos que garantiam o voto feminino foram apresentados, mas não alcançaram êxito no Congresso.

Já em 1927, no Rio Grande do Norte, foi eleito ao cargo de governador o militante pelo direito ao voto feminino, Juvenal Lamartine. Como governador, logrou êxito na inclusão dos direitos políticos das mulheres na reforma da Constituição Estadual, promovida pela Assembleia Legislativa (SCHUMAHER, 2000).

Assim, as mulheres do Rio Grande do Norte foram as primeiras a exercerem o direito ao voto, bem como o direito de registrar candidaturas e concorrer às disputas eleitorais. Em 1928, foram realizadas as primeiras eleições com a participação de mulheres no Rio Grande do Norte, quando elegeu-se Luiza Alzira Soriano, a primeira prefeita do Brasil, na cidade de Lajes (SALGADO; GUIMARÃES; MONTE-ALTO, 2018).

Após esse primeiro avanço na conquista do sufrágio feminino, em 1932 foi promulgado o Código Eleitoral, reconhecendo, além do voto secreto, o direito de mulheres serem votadas e o cadastramento eleitoral a partir de dezoito anos. Entretanto, o voto só era obrigatório para mulheres detentoras de cargo público. Assim, para maior parte da população feminina, o voto era facultativo (SALGADO; GUIMARÃES; MONTE-ALTO, 2018).

Com a promulgação da nova Constituição, em 1934, as mulheres exerceram pela primeira vez o direito de votar e de se candidatar nas eleições da Assembleia Nacional Constituinte. Diante desse avanço no âmbito do direito eleitoral, o Brasil tornou-se o quarto país da América a estabelecer o voto feminino (BUONICORE, 2009, p. 205).

No entanto, a participação da mulher na política brasileira mal começou e logo foi interrompida, já que, em 1937, ocorreu o golpe que culminou no Estado Novo, e deu início a um regime ditatorial marcado pela extinção do Poder Legislativo por quase dez anos. O sufrágio feminino conquistado com a criação do Código Eleitoral e a Constituinte de 1934 foram rompidos. A FBPF sofreu uma grande afronta e algumas de suas dirigentes chegaram a ser presas, não conseguindo mais ter expressão no cenário brasileiro. 
Apenas em 1945, a democracia foi retomada, e a participação feminina novamente exercida na Assembleia Constituinte. Muitas mulheres concorreram a diversos cargos políticos, sendo que algumas foram eleitas para Assembleias Estaduais e Câmaras Municipais (PINHEIRO, 2007, p. 65). Contudo, nenhuma mulher conseguiu ser eleita para exercer mandato no Congresso.

Já em 1964, sobreveio a instauração do Golpe Militar e a ocorrência de eleições indiretas. A partir disso, deu-se início a uma radicalização da política de repressão, censura, prisões arbitrárias, tortura, extinção de

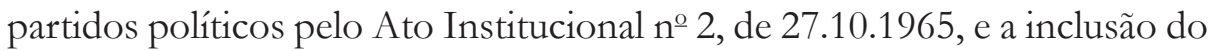
bipartidarismo (SCHUMAHER, 2000).

Ainda na época da Ditadura Militar, em 1966, na conjuntura de eleições indiretas, apenas seis mulheres foram eleitas deputadas federais, dentre as quais, três somente concorreram em decorrência da morte de seus cônjuges. Contudo, em janeiro de 1969, tiveram seus mandatos cassados com base no Ato Institucional n 5 (AI-5) (SCHUMAHER, 2000).

O envolvimento da mulher na política foi repleto de muita oscilação. Nas eleições de 1970, apenas uma deputada federal foi eleita. Já no pleito de 1974, apesar de inúmeras terem realizado suas candidaturas, não conseguiram ser eleitas. Nesse período, o Congresso foi fechado três vezes, o que pode ter afetado a campanha das mulheres (BITHIAH; RABAT, 2012, p. 77-78).

Após anos de muita repressão, em 1979 foi aprovada a Lei da Anistia (Lei no 6.683), que reverteu punições aos cidadãos brasileiros que, entre os anos de 1961 e 1979, foram considerados criminosos políticos pelo regime militar, e aos militares que praticaram crimes. A anistia trouxe ao país uma maior liberalização, menor repressão e a volta do pluripartidarismo.

Já na década de 1980, com a volta da normalidade política, em 1986, ocorreram eleições gerais para compor o Congresso. Naquela eleição, 29 mulheres conseguiram ser eleitas, o maior número desde o início da participação feminina no espaço político. Essas parlamentares se uniram em prol dos interesses das mulheres durante sua participação na Assembleia Constituinte, autodenominando-se bancada feminina (PINTO, 2003, p. 125-132).

A formação da bancada feminina no Congresso criou uma atuação conjunta das mulheres que foi se tornando gradativamente mais regular, ao 
mesmo tempo em que a coordenação se tornava formalmente mais bem definida. Foi uma iniciativa fundamental para amplificar a voz das mulheres na Câmara dos Deputados.

Finalmente, em 1988, decorreu a instauração de um novo Poder Constituinte, que aboliu a supremacia masculina e as desigualdades legais entre os gêneros. Isso só foi possível devido à atuação marcante das mulheres pela inclusão dos seus direitos na Constituição (PINTO, 2003, p. 78). E já nas primeiras eleições após a Constituição de 1988, houve um recorde de mulheres eleitas: desta vez, trinta deputadas federais, com a presença de uma mulher à frente do Ministério da Economia.

Posteriormente, nas eleições de 1994, trinta e três mulheres foram eleitas para o cargo de deputada federal. Nesse ano, foi eleita, no Estado do Maranhão, a primeira mulher governadora de um estado brasileiro, Roseana Sarney, reeleita posteriormente em 1998. À vista disso, apesar da conquista das mulheres ao sufrágio feminino, sua representação no cenário político era ínfima. As mulheres, em geral, detinham menos de dez por cento dos cargos na câmara dos deputados, no senado federal, nas prefeituras brasileiras e nas câmaras de vereadores, tornando-se necessária a criação de ações afirmativas que impulsionassem a participação das mulheres na política (BITHIAH; RABAT, 2012, p. 176-180).

\section{Participação da mulher da política brasileira: cotas partidárias}

A inserção das mulheres na vida política se deu a partir de uma luta constante enfrentada por mulheres de diversas classes sociais que se uniram com o objetivo de promover a cooperação entre elas na defesa das causas relativas ao progresso do país e de sua cidadania. Essa luta pela representatividade feminina é o principal marco de uma reestruturação dos papéis tidos como tipicamente masculinos e da busca por políticas públicas, a fim de dar efetividade no debate por igualdade, uma vez que um maior acesso feminino ao Congresso ensejaria uma melhora na qualidade da representação da sociedade, contribuindo para a redução da desigualdade.

Nesse sentido, com vistas a combater a afincada desigualdade de gênero na política, destaca-se a criação de ações afirmativas que visem expandir a representação da mulher no cenário político. Dentre essas ações, sobressai-se a criação das cotas de gênero, no ano de 1995, instituída pela 
Lei $\mathrm{n}^{\circ}$ 9.100. O dispositivo estabeleceu a primeira reserva de vagas para mulheres nas listas de candidaturas em eleições proporcionais, prevendo que cada partido apresente no mínimo $20 \%$ de candidatas. Na mesma lei, também foi aprovada a ampliação do número de vagas na lista eleitoral para 120\% do total de cadeiras de disputa (MIGUEL, 2000, p. 42-44).

O percentual de 20\% para participação de mulheres não era de cumprimento obrigatório para os partidos políticos, já que, caso não pudessem preencher o percentual mínimo com candidatos do sexo feminino, poderiam deixá-lo em aberto. Dessa forma, as cotas deixaram de ser caracterizadas como reserva de vagas e se tornaram cotas suplementares (ARAUJO, 1998).

Nas eleições municipais de 1996, o Tribunal Superior Eleitoral (TSE) considerou que não poderia obrigar os partidos a preencher as vagas reservadas às mulheres, mas apenas para deixá-las reservadas, não podendo ser preenchidas por homens. Contudo as eleições apresentaram um percentual de candidatas próximo da cota mínima estabelecida, alcançando 18\% do total de candidatos (ARAUJO, 1998).

Apesar do número de mulheres candidatas nas eleições de 1996 ter se aproximado do percentual estabelecido pelas cotas, a bancada feminina continuou lutando pelo aumento das cotas de gênero. Assim, em 1996, foi novamente levantada a pauta das cotas para as eleições gerais de 1998, com o objetivo de expandi-las no âmbito Estadual e Federal.

A partir disso, no final de 1997, foi aprovada a nova Lei Eleitoral $n^{\circ}$ 9.504/1997, que estabeleceu regras permanentes para as eleições, incluindo as de 1998. A Lei das Eleições foi aprovada com a redação assegurando uma cota mínima de 30\% e máxima de 70\% para cada gênero, com um artigo nas disposições transitórias que excepcionava esta proporção para $25 \%$ e 75\% para as eleições de 1998. Dessa maneira, o preenchimento das cotas permaneceu igual ao regime aplicado em 1996, isto é, os partidos deveriam apenas reservar o percentual de vagas para as mulheres (MIGUEL, 2000, p. 46-48). Além disso, o número de vagas nas listas eleitorais passou a ser de $150 \%$ das cadeiras em disputa nas eleições proporcionais.

Nas eleições proporcionais, o eleitor pode votar tanto no candidato quanto no partido ou coligação, ou seja, aplica-se o modelo de lista aberta em que o eleitor escolhe seu candidato entre aqueles apresentados 
em lista não ordenada pelo partido político, podendo optar por votar nominalmente em seu candidato ou somente na legenda partidária (SANTOS; BARCELOS, 2015, p. 16).

Nessa sequência, o cálculo do número de candidatos que cada partido ou coligação pode registrar toma por base a quantidade de vagas a serem completadas na respectiva Casa Legislativa. O cômputo é realizado da seguinte forma: caso tenham sido abertas 30 vagas em uma eleição, por exemplo, cada partido poderia registrar até 45 candidatos $(30 \times 150 \%=45)$ para o cargo que está em aberto (GOMES, 2017, p. 345) ${ }^{1}$.

A formulação das cotas partidárias com percentual igual ao aumento das vagas totais que cada partido pode registrar de trinta por cento na disputa eleitoral indica de forma explícita que os legisladores temiam a redução das candidaturas masculinas e adotaram essa medida como precaução para que não perdessem seu "espaço" no cenário político.

\subsection{A sub-representação feminina e seu impacto na aplicação das cotas de gênero}

Apesar da implantação das cotas partidárias, ainda não houve um aumento significativo na representação feminina na política. Isso porque, de acordo com dados do Tribunal Superior Eleitoral (TSE), as mulheres desde a conquista dos seus direitos políticos não conseguiram ultrapassar 15\% do total de Deputados Federais. Nas eleições gerais de 2018, apenas 290 candidatas foram eleitas, representando um total de $16,20 \%$ do total de eleitos.

\footnotetext{
${ }^{1}$ Existem duas exceções a essa regra definida pelo artigo 10 da Lei de Eleições. A primeira exceção (prevista no inciso I do aludido artigo 10) refere-se às unidades da Federação em que o número de lugares a preencher na Câmara dos Deputados não exceder a doze, caso em que cada partido ou coligação poderá registrar candidatos a Deputado Federal e a Deputado Estadual ou Distrital até $200 \%$ das respectivas vagas. A segunda exceção (prevista no inciso II) refere-se aos Municípios de até cem mil eleitores, caso em que, havendo coligação, esta poderá registrar candidatos no total de até $200 \%$ (duzentos por cento) do número de lugares a preencher.
} 


\section{Tabela 1 EVOLUÇÃO DA BANCADA FEMININA NA CÂMARA DOS DEPUTADOS}

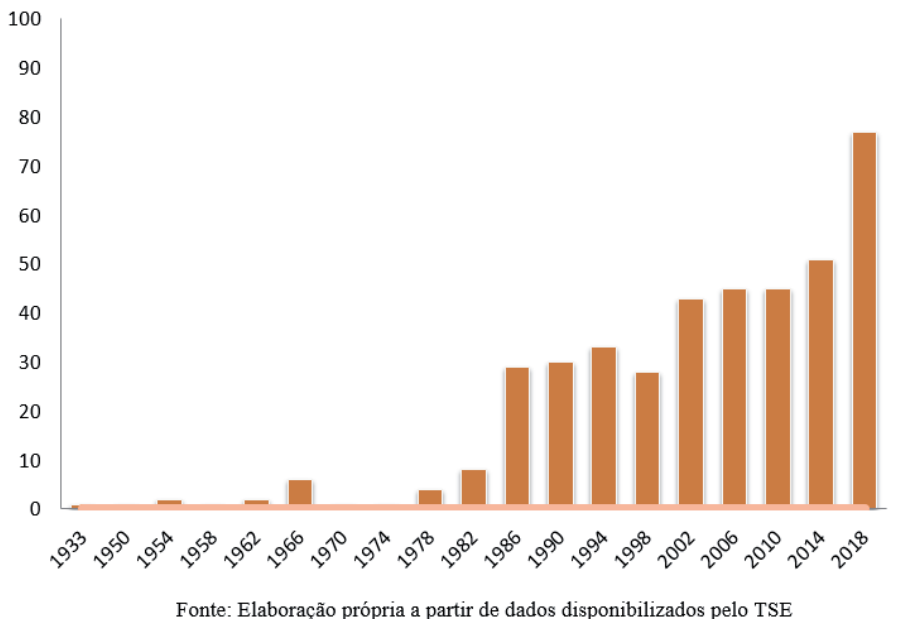

Desde a implementação das cotas de gênero, várias medidas vêm sendo adotadas para potencializar a participação feminina na política. $\mathrm{O}$ Congresso Nacional, rotineiramente, realiza reformas eleitorais e, no ano de 2009, a Lei das Eleições passou por uma minirreforma eleitoral que resultou na promulgação da Lei n²12.034/2009.

Em relação às cotas, foi dada nova redação ao $\ 3^{\circ}$ do art. 10 da Lei 9.504, substituindo-se a expressão "deverá reservar" para "preencherá" o mínimo de $30 \%$ e o máximo de $70 \%$ das candidaturas para cada sexo. Além disso, junto a essa medida também foram aprovadas as destinações de $10 \%$ do tempo de propaganda partidária às mulheres e de 5\% dos recursos do fundo partidário à criação e à manutenção de programas de promoção e difusão da participação política para mulheres (PINTO; BERTOT'TI; FERRAZ. 2018, p. 128-129).

Neste último caso, se o partido descumprir a medida, estará obrigado a acrescentar mais 2,5\% dos recursos do fundo no ano subsequente, ficando impedido de utilizá-los para outro fim.

Essas regras foram utilizadas nas eleições de 2010, mas o resultado eleitoral indicou que a minirreforma não alcançou o objetivo de aumentar a representação feminina, pois foram eleitas apenas 45 mulheres para a Câmara dos Deputados.

Já em 2015, a Lei no 13.165/2015, criada com o objetivo de incentivar a participação feminina na política, previu, em seu artigo 9우 que, 
nas eleições subsequentes, os partidos deveriam reservar, no mínimo 5\% e no máximo $15 \%$, do montante partidário destinado ao financiamento das campanhas eleitorais para aplicação nas campanhas de suas candidatas.

No ano de 2017, também foram editadas normas para as eleições gerais de 2018. Entretanto, nenhum dispositivo foi especialmente destinado a promover a participação feminina na política.

À vista disso, o Plenário do TSE, em agosto de 2018, reconheceu a aplicação das cotas partidárias ao Fundo Especial de Financiamento de Campanha e na distribuição do tempo de propaganda. Dessa forma, os partidos políticos deveriam destinar pelo menos 30\% dos recursos do Fundo Eleitoral e o mesmo percentual deve ser considerado em relação ao tempo destinado à propaganda eleitoral gratuita no rádio e na TV.

Essa decisão unânime dos ministros ocorreu em resposta à consulta formulada por um grupo de quatorze parlamentares - oito senadoras e seis deputadas federais. O questionamento foi levado ao Tribunal em decorrência da decisão do Supremo Tribunal Federal (STF) nos autos da Ação Direta de Inconstitucionalidade (ADI) no 5617/2018, de relatoria do Ministro Edson Fachin. Em síntese, foi determinada a destinação de, pelo menos, 30\% dos recursos do Fundo Partidário às campanhas de candidatas, sem fixar percentual máximo.

Além disso, o TSE firmou entendimento de que em relação ao não atendimento dos percentuais estabelecidos pelas cotas partidárias quando da formalização do pedido de registro, é possível cumprir os percentuais estabelecidos pelas cotas em data posterior à do limite para requerimento de candidaturas, desde que isso seja realizado até trinta dias antes do pleito, tempo disposto no artigo 10, \5\% , da Lei no 9.504/1997².

Nesse sentido, os partidos políticos podem realizar a adequação posteriormente, acrescentando ou retirando da lista apresentada a quantidade de nomes que se fizer necessária. Vale pontuar que apenas os partidos políticos podem efetuar esse reajuste, pois a indicação de nomes para a disputa do certame é ato privativo dos partidos, de acordo com o artigo $17 \mathrm{da}$ Constituição Federal de 1988 (VALENTE; SALES, 2016, p. 42-44).

Contudo, se os percentuais legais não forem atendidos, deverá o juiz notificar o partido político para, em até 72 horas, regularizar a situação,

2 TRIBUNAL SUPERIOR ELEITORAL - Acórdão em REspe no 107079/BA - PSS 11-12-2012. 
nos termos do artigo $11, \sqrt{\int} 3^{\circ}$ da Lei 9.504/97. Caso, não haja a regularização, haverá o indeferimento do Demonstrativo de Regularidade Partidária (DRAP), prejudicando todos os pedidos de registro de candidatura apresentados ${ }^{3}$.

Nesse sentido, José Jairo Gomes explica que, se não houver número suficiente de mulheres no partido para preencher os percentuais, a agremiação poderá indicar para as vagas sobejantes candidatos do sexo oposto:

É defeso ao partido ou à coligação indicar para as vagas sobejantes candidatos do sexo oposto àquele a que elas se destinavam, visto que não poderá preencher com candidatos masculinos às vagas destinadas a candidatas femininas e vice-versa. (...) O que cumpre aos partidos é aprimorar seus quadros, aumentando o número de filiados de ambos os sexos (GOMES, 2017, p. 351).

A mesma regra não será aplicada no caso de os percentuais não serem cumpridos quanto à formalização do pedido de registro de candidatura, mas posteriormente. Ou seja, antes do pleito e por razões não imputáveis à agremiação, pois o indeferimento posterior de candidaturas não infirma a observância do sistema de cotas pelo partido. Por outro lado, se o desfalque na porcentagem da cota em razão de renúncia de candidaturas femininas for posterior ao momento do registro, o partido não viola o limite de $30 \%$ previsto, porque tal porcentagem foi atendida quando da realização do registro (GOMES, 2017, p. 351-352).

A reserva de cotas de gênero, os avanços conquistados através das decisões do TSE e as mudanças realizadas na legislação visam evitar que a distribuição dos recursos se dê de forma discriminatória pelos partidos, perpetuando uma desigualdade na promoção de candidatas que tradicionalmente não desfrutam de espaço relevante no cenário político dominado por homens.

\subsection{Dos obstáculos para maximização da representação feminina e a (in)efetividade das cotas de gênero partidárias}

Conforme explanado nas seções anteriores, a previsão de cotas para candidatas no Brasil, em conjunto com as demais mudanças normativas, não têm surtido os efeitos desejados no incremento de participação feminina na política. O Brasil se encontra bem abaixo da média na América

${ }^{3}$ TRIBUNAL SUPERIOR ELEITORAL - Acórdão em REspe no 2939/PE - PSS 6-11-2012. 
Latina, ocupando atualmente a $133^{\underline{a}}$ posição no ranking de participação de mulheres no Parlamento, elaborado pela ONU Mulheres em parceria com a União Interparlamentar (UIP), que analisou 193 países.

A partir desse contexto, é importante discutir alguns fatores que influem para que as cotas não tenham conseguido maximizar a representatividade feminina no Brasil. Entre os motivos que explicam a baixa representação feminina na política estão os fatores histórico-culturais, pois, embora a visão social sobre a mulher tenha se desenvolvido, ainda há na sociedade a manutenção de uma mentalidade patriarcal que entende que apenas devem ser destinadas às mulheres atividades relacionadas à família ou ao lar.

Ante os problemas culturais, outros fatores impeditivos estão na própria redação da Lei. O parágrafo 3º, do art. 10, da Lei nº 9.504/97, alterado pela Lei $\mathrm{n}^{\circ}$ 12.034/09, estabeleceu que cada partido deverá preencher um mínimo de 30\% e um máximo de 70\% para candidaturas de cada sexo. Contudo, não há previsão normativa de sanções a serem aplicadas aos partidos que descumpram o percentual estabelecido pelas cotas de gênero.

De acordo com Cristiane Aquino (SOUZA, 2014), outro motivo que inibe a participação feminina, está atrelado à cláusula de escape presente na Lei 9.504/97, que autoriza os partidos a aumentarem o número de candidatos. Com essa legislação, o total de candidatos que pode ser apresentado por cada partido é de 150\%. Isso importa na diluição das cotas femininas, pois o aumento do número de candidatos se dá em $50 \%$, o que representa mais que a porcentagem mínima de 30\% estabelecida para cada sexo pelas cotas, isto é, os partidos apresentam candidatos acima do número de vagas a preencher ${ }^{4}$.

Além dos aspectos relacionados com a própria fragilidade normativa da lei, um dos fatores que contribui para a não aplicação das cotas no Brasil consiste na ausência de apoio dos partidos políticos nas candidaturas femininas. As mulheres, em regra, não são prioridade dos partidos no

\footnotetext{
${ }^{4}$ Exemplo prático: Se em certo local elegem-se dez deputados, cada partido está autorizado a postular quinze candidaturas, de maneira que, ao menos quatro destas devem ser contempladas por mulheres (ou homens). Assim, o partido estaria habilitado a apresentar uma candidatura composta por onze homens e quatro mulheres $(150 \%)$, em vez de sete homens e três mulheres $(100 \%)$. Portanto, o partido possui garantida a possibilidade de propor um número de homens suficiente para atender à demanda de deputados a eleger, sem que seja necessário investir em candidaturas femininas. Isso representa um incentivo ao descumprimento da lei e, em caso de cumprimento, a que esta não tenha um impacto positivo relevante nas oportunidades eleitorais das mulheres candidatas (SOUZA, 2014).
}

Resenha Eleitoral (Florianópolis), v. 23, n. 1, p. 139-164, 2019 
que tange ao investimento intrapartidário, isso porque, no que se refere à escolha de candidatos, os partidos tendem a dar preferência àqueles que dispõem de recursos próprios ou que são providos por seus apoiadores (FREITAS; 2016, p. 138).

Assim, outra explicação para a ausência de mulheres na esfera política - sob influência dos partidos políticos - é a desistência das candidatas ao pleito antes das eleições, o que pode ser consequência, muitas vezes, da escolha realizada pelos partidos de candidatas "laranjas" - que não têm chance real de eleição. Nas candidaturas falsas, muitas mulheres são apresentadas como candidatas pelos partidos sem conhecimento nem consentimento delas, seja por meio de pedido de registro de candidatura com assinatura falsificada, seja por requerimento firmado por dirigentes partidários, sem procuração com poderes especiais (SANTOS; BARCELOS, PORCARO 2018, p. 133).

Dessa forma, as candidatas registradas não possuem qualquer compromisso com a vida política, ou intenção de participar de fato da campanha, figurando fictamente no processo eleitoral e entrando apenas formalmente na composição da lista, servindo de "laranjas" para garantir a participação no pleito dos outros candidatos.

De acordo com dados fornecidos pelo Tribunal Superior Eleitoral, em 2016, mais de 16.000 candidatos terminaram a eleição sem ter recebido sequer um voto, ou seja, nem o próprio candidato votou em si, mesmo concorrendo com o registro deferido. Desse total de candidatos sem votos, 14.417 eram mulheres e apenas 1.714 eram homens (TSE, 2018).

A fim de impedir que esse tipo de candidatura seja efetivada, os Tribunais Eleitorais têm adotado o entendimento de que o lançamento de candidaturas femininas fictícias é uma fraude à legislação eleitoral, e, portanto, passível de cassação do diploma de todos os candidatos diretamente beneficiados pelo ato ilegal, com a consequência da inelegibilidade para candidatos representados que sejam considerados responsáveis pela conduta fraudulenta 5 .

Essa jurisprudência firmada pelo Tribunal Regional Eleitoral de São Paulo só foi possível porque, em 2013, ocorreu o julgamento do Recurso Especial Eleitoral no Estado do Piauí, REsp nำ1-49/PI, admitindo

\footnotetext{
${ }^{5}$ DECISÃO DO TRE-SP: Recurso Eleitoral no ${ }^{\circ}$ 370-54.2016.6.26.0173, Rel. Claudia Lucia Fonseca Fanucchi.
} 
mudanças procedimentais capazes de ampliar o controle das candidaturas fictícias, e determinando que a apuração do cumprimento das cotas eleitorais de gênero possa ser feita tanto no momento do registro das candidaturas quanto no decorrer das campanhas eleitorais (BUENO; COSTA, 2018).

À vista dos obstáculos à participação da mulher no cenário político, que ocorre sem apoio efetivo e destinação de recursos por parte dos partidos, aponta-se o fato de ter sido sancionada a Lei no 13.831, de 2019, que altera as regras referentes à prestação de contas dos partidos políticos e concede mais autonomia em sua organização interna e sua movimentação financeira.

A referida Lei anistia as legendas que não cumpriram a regra de incentivo à participação política das mulheres, de forma que os partidos que não aplicaram o mínimo de 5\% do Fundo Partidário para promover a participação política das mulheres, entre 2010 e 2018, não poderão ter suas contas rejeitadas ou ser alvo de qualquer outra penalidade, caso tenham incentivado a participação feminina de algum modo.

A aprovação dessa norma é um retrocesso, uma vez que torna sem efeito o trabalho dos Tribunais Eleitorais que buscam avançar na fiscalização da aplicação devida das normas, impondo sanções aos partidos que não cumprem o percentual mínimo de 5\% dos recursos do Fundo Partidário. Resta claro que a participação da mulher na política, além de não ser prioridade dos partidos, também não é a dos Poderes Legislativo e Executivo, uma vez que ao invés de avançar com as medidas já existentes, estagnam - e retrocedem - os pequenos avanços alcançados.

Não obstante ao exposto, outro motivo que dificulta a eleição de mulheres no Brasil é a adoção do sistema proporcional com listas abertas, considerando que conferem um caráter individualizado à competição. Segundo, José Jairo Gomes (2017, p. 157), no sistema de lista aberta é o eleitor que define quais são os candidatos eleitos dentre os integrantes da lista montada pelo partido. Dessa forma, são os candidatos mais votados que irão ocupar as cadeiras destinadas ao partido.

A lista aberta dificulta as candidaturas femininas, pois o voto é personalizado, o eleitor vota no candidato e não no partido. Isso faz com que as mulheres que precisam contar com recursos próprios - tanto financeiros como de acesso aos meios de comunicação, contatos pessoais, etc. - não consigam efetivamente chegar com a sua imagem até o eleitor, tendo em vista que competem, na maioria das vezes, com os candidatos homens 
de seu partido, os quais, em geral, possuem mais redes de apoio, intra ou extra partidárias. Por fim, isso pode contribuir para que muitas mulheres desistam de apresentar-se como candidatas (SOUZA, 2014).

Posto isso, nota-se que ainda há muitos problemas a serem enfrentados pelas mulheres na busca por igualdade na representação política. Assim, para que as cotas alcancem seu objetivo, torna-se essencial que sejam adotadas políticas públicas que possam resultar de fato na conversão do número de mulheres candidatas em mulheres eleitas.

\section{As cotas eleitorais de gênero no direito comparado e as novas diretrizes para as cotas eleitorais de gênero no Brasil}

O Brasil caminha devagar na busca por uma participação feminina efetiva na política. Apesar das cotas já estarem presentes no sistema eleitoral há mais de vinte anos, a representação feminina no Congresso brasileiro ainda é uma das menores em toda América Latina. Nesse sentido, é importante verificar como funciona o sistema eleitoral de outros países e a forma como se constituíram as cotas de gênero.

\subsection{Argentina - pioneira na implementação das cotas}

A Argentina é uma república federal integrada por vinte e três províncias e um distrito federal autônomo (Buenos Aires), que conservam alguns poderes não pertencentes ao Governo Federal. O Poder Executivo Nacional é exercido por um Presidente e um Vice-Presidente eleitos por um período de quatro anos através do voto direto dos cidadãos, sendo possível a reeleição por um só período consecutivo. Já o Poder Legislativo é formado por um Congresso Nacional bicameral. A Câmara de Deputados conta com 257 integrantes eleitos para um período de quatro anos, enquanto o Senado Federal é composto por 72 legisladores com mandatos de seis anos.

A Argentina, diferentemente do Brasil, adota como sistema eleitoral o proporcional, com listas fechadas e bloqueadas em que os partidos decidem, antes das eleições, a ordem dos candidatos. $\mathrm{O}$ eleitor não vota em nomes, mas apenas em um dos partidos. Lá, portanto, os eleitores não exercem qualquer interferência nos nomes que efetivamente ocuparão as cadeiras legislativas (GOMES, 2017, p. 157). 
As cotas de gênero foram implementadas na Argentina, em 1991, por meio da Lei no 24.012, denominada Ley de Cupos, que tornou obrigatória a cota mínima de 30\% de mulheres nas listas de candidatura e a previsão de sanções aos partidos em se não havendo o cumprimento do percentual estabelecido nenhuma lista seria oficializada. (LOPEZ; NETO; OLIVEIRA, 2017, p. 210).

A fim de complementar o dispositivo, o Presidente da Argentina à época, Juan Perón, promulgou, em 1993, o Decreto nº. 379. O referido decreto estabeleceu que a cota de $30 \%$ deveria ser entendida como quantidade mínima e que haveria de ser incluída pelo menos uma mulher para cada dois homens. O Decreto especificou, ainda, que, no caso de renovação de apenas dois cargos, um deles deveria ter como candidata uma mulher.

Nas eleições de 1993 para Câmara dos Deputados, foram aplicados a Lei e o Decreto mencionados, e a maioria dos partidos cumpriu a exigência de $30 \%$ de candidatas, porém posicionaram as mulheres nos últimos lugares da lista, de maneira que não tivessem possibilidades reais de serem eleitas.

Diante disso, no ano 2000, o Presidente, De la Rúa, promulgou o Decreto n․ 1246/00, a fim de substituir o vigente ( $\mathrm{n}^{\circ}$ 379/93). O novo decreto estipulou que as cotas femininas se aplicam a todos os cargos eletivos de deputados, senadores e constituintes nacionais, e que a cota só se considera cumprida quando aplicada em função do número de cargos que cada partido ou aliança renova na eleição correspondente.

Além disso, o Decreto também estabeleceu que qualquer cidadão tem a legitimidade de impugnar uma lista de candidatos perante a Justiça Eleitoral, havendo previsão de sanção caso a candidata esteja posicionada num lugar posterior ao que lhe corresponde na lista. Além disso, caso ocorra qualquer irregularidade, o juiz eleitoral notificará o partido, que terá $48 \mathrm{~h}$ para reposicionar a candidata. Caso não o faça, o Tribunal a reposicionará por ofício, e, se necessário também nomeará as mulheres seguintes na ordem da lista. Por fim, ressalta que a lista de suplentes também deve cumprir a cota.

A implementação dessas ações normativas foi de extrema relevância no avanço da representação feminina na Argentina. Entretanto, Patrícia Rangel (2012, p. 175-178) destaca dois principais problemas na aplicação das cotas na Argentina: o primeiro refere-se ao percentual de 30\% estabelecido pelas cotas, uma vez que, apesar de efetivas, tornaram-se uma limitação, pois apenas 30\% das vagas são pra mulheres; o segundo relaciona-se ao 
fato de que as mulheres não ocupam cargos altos no Congresso, isto é, não lideram as coligações e não conseguem chegar à presidência da Câmara. Em síntese, a participação feminina só ocorre para cargos baixos do Congresso.

Assim, apesar das ressalvas, destaca-se que a eficiência das cotas se dá em virtude de um conjunto de fatores, dentre eles: sistema eleitoral proporcional com listas fechadas e bloqueadas, previsão de mandato de posição, existência de sanções legais para o descumprimento da norma, promulgação de Decretos para favorecer uma eficaz interpretação e aplicação da lei e, por fim, decisões do poder jurisdicional que exigem o cumprimento da cota e possibilitam a adequada eficácia da lei.

\subsection{Bolívia - paridade de gênero}

A Bolívia é uma República unitária e adota para seu governo a forma democrática representativa. O país está estruturado política e administrativamente em nove departamentos, 112 províncias, 327 municípios e 1.384 cantões, sendo onze desses municípios autônomos indígenas. O Poder Executivo Nacional é exercido por um Presidente e um Vice-Presidente eleitos por um período de cinco anos, pelo voto direto do povo no primeiro turno e, caso o candidato não atinja 50\% dos votos, com segundo turno, que será decidido pelo parlamento, sendo possível a reeleição por dois períodos consecutivos.

A Assembleia Legislativa é bicameral, formada pela Câmara dos Deputados, composta por 130 membros, e pela Câmara dos Senadores, com 36 membros, ambos diretamente eleitos para mandatos de cinco anos. A Bolívia, congênere à Argentina, adota o sistema de lista fechada, que permite o controle do impacto das cotas de candidatos sobre os resultados das eleições, pois exige que os nomes sejam lançados nas listas, intercalando-se homens e mulheres (SANTOS, 2016).

As mulheres bolivianas conquistaram o direito de votar em 1952, vinte anos depois de o Brasil reconhecer o sufrágio feminino (MARTINI, 2015). Em 1979, foi eleita a primeira deputada, trinta anos após a conquista do voto. Após essa eleição, sindicatos formados por mulheres deram início à Confederação Nacional de Mulheres Campesinas e Indígenas da Bolívia - "Bartolina Sisa". A forte atuação dos movimentos femininos na busca pela garantia de direitos políticos e sociais foi um fator determinante na conquista dos direitos políticos e na implantação das cotas partidárias. 
As cotas foram criadas no país em 1997, por meio da Lei nº 1779 da reforma eleitoral, que introduziu no ordenamento jurídico boliviano a obrigatoriedade para que partidos políticos tivessem ao menos $30 \%$ de mulheres em suas listas nacionais de candidatos, distribuídas de tal forma que ao menos um em cada três candidatos da lista fosse do sexo feminino. A norma estabeleceu ainda, como obrigação dos Partidos Políticos: Promover la igualdad de oportunidades de sus militantes, hombres y mujeres; así como la efectiva participación de la mujer en los órganos de dirección partidaria y en la nominación de candidaturas para cargos de representación popular. (SANTOS; BARCELOS, p. 19)

As cotas elevaram o número de candidatas e, consequentemente, número de mulheres eleitas. Contudo, os resultados expressivos foram atingidos após as reformas introduzidas a partir do ano de 2006, quando o Presidente Evo Morales assumiu a chefia do Poder Executivo Nacional. Em 2009, foi promulgada a "Nueva Constitución Politica Del Estado Plurinacional de Bolivia”, destacando a importância da participação equitativa e em igualdade de condições para homens e mulheres. Já no ano de 2010, a Lei

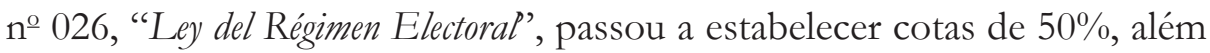
da obrigatoriedade de apresentação de listas de candidatos intercalando-os em razão do sexo.

A “Ley del Régimen Electoral' detalhou inúmeras regras para garantir igualdade, paridade e alternância, inclusive nos casos de candidatura única na circunscrição. A Lei determina que, caso a lista contenha número ímpar de candidatos, a preferência deverá ser dada às mulheres. Além disso, estipula que, em caso de não admissão da lista completa de candidaturas, o partido será notificado sobre a rejeição à organização política e, assim, deverá emendar em um prazo máximo de setenta e duas horas contados da notificação.

Dessa forma, percebe-se que, conforme ocorre no Brasil e na Argentina, é conferida a oportunidade de emenda às listas que não observarem os princípios da igualdade e alternância. Entretanto, transcorrido o prazo sem que as correções sejam feitas, a consequência é a desaprovação de toda a lista, de maneira que, caso o partido não obedeça ao regime das cotas, sua lista inteira será punida (VENTURINI; VILLELA, 2016).

A Bolívia adotou, após a implementação das cotas, uma série de normas que, juntas conseguiram colocar o país em terceiro lugar no ranking mundial de representação feminina, com percentual de 53,1\% da composição da Câmara dos Deputados e 47,2\% na Câmara do Senado. 
Assim, uma das razões que explica os bons resultados obtidos é que a Bolívia adota um sistema misto de correção, em que parcela dos deputados e senadores é escolhida por meio do sistema de representação proporcional com listas fechadas. Sistema diferente do adotado pelo Brasil, que possui listas abertas que permitem que fiquem livres as vagas destinadas às mulheres, ampliando o número de candidatos em cada lista. $\mathrm{O}$ mecanismo da alternância, adotado pela Bolívia, impede que os grupos partidários manejem a ordem de candidatos na lista com o intuito de privilegiar as candidaturas masculinas, deixando os nomes das candidatas nas últimas posições, sem chances de eleição.

Outro fator importante para o aumento da representatividade feminina no país é a punição aplicada aos partidos políticos que não respeitarem o mínimo de candidaturas femininas. Nesse aspecto, a política de cotas boliviana também difere da brasileira, haja vista que a legislação não prevê qualquer repreensão aos partidos que não cumprem as cotas.

A Bolívia está à frente da Argentina e do Brasil na representatividade feminina na política, já que mais de $50 \%$ da composição do seu parlamento é feminino. A profundidade das mudanças que a legislação eleitoral boliviana sofreu nos últimos tempos com o fito de introduzir mais mulheres no debate público institucionalizado fez com que a política na Bolívia tenha se tornado um ambiente profícuo para a efetivação da igualdade de gênero, especialmente, em razão da alteração legislativa, que instituiu a paridade entre homens e mulheres na disputa eleitoral através das cotas de cinquenta por cento.

\section{Considerações finais}

As considerações aduzidas ao longo do presente ensaio demonstram que as cotas partidárias de gênero no Brasil são ineficazes, uma vez que as mulheres representam menos de $30 \%$ do total de cadeiras do Congresso Nacional.

A ausência de avanços na representação feminina se deve a uma série de fatores ligados à formação cultural do país, e, além disso, ao sistema eleitoral adotado, à inexistência de sanções legais aos partidos nos casos de descumprimento das cotas e ao aumento do número de possibilidade de oferta de candidatos pelos partidos com a apresentação de candidaturas fictícias (laranjas). 
Ademais, outra importante razão para a ausência de mulheres na esfera política se deve ao fato de que apenas a existência de uma lei que estipule um percentual a ser preenchido por mulheres não é suficiente para efetivar a representatividade feminina no espaço político. Em verdade, o sistema atual tem contribuído para que o fenômeno das candidaturas "fantasmas", diante da inexistência de políticas afirmativas que, de fato, possam maximizar não apenas o amplo acesso das candidatas ao pleito eleitoral, mas lhes garantir condições materiais de igualdade com relação às candidaturas masculinas.

O que se percebe é que, no âmbito interno dos próprios partidos políticos no Brasil, não há uma preocupação, tampouco políticas afirmativas consistentes que visem aumentar o espectro político de candidatas. A única preocupação dos partidos está atrelada ao cumprimento dos números mínimos fixados pela legislação eleitoral para que não sejam submetidos às punições dela decorrentes. É preciso mudar a mentalidade que ronda a política intrapartidária e promover ações afirmativas que, de fato, maximizem a participação feminina na política, garantindo-lhes amplo espaço de participação.

E, assim, diante desse cenário de grande luta das mulheres pela conquista dos direitos políticos para que pudessem participar da vida pública, torna-se um imperativo que seja acrescido na Lei Eleitoral a obrigação de os partidos políticos concernente na distribuição de no mínimo trinta por cento do Fundo Partidário para o financiamento de candidaturas de mulheres, seguindo a orientação já traçada pelo TSE brasileiro recentemente.

Do mesmo modo, será extremamente interessante que o Brasil, à semelhança do sistema de cotas da Bolívia, modifique o sistema de cotas atual para prever, por exemplo, o percentual mínimo de $50 \%$ (cinquenta por cento) de vagas destinadas às mulheres, ou, adotando o modelo da Argentina, tendo em vista os bons resultados alcançados na participação feminina e, com isso, alcançar a tão sonhada paridade de gênero.

\section{Referências}

ALVIM, Frederico Franco. Curso de direito eleitoral. 2ed. Curitiba: Juruá, 2016. ARAÚJO, Clara. Mulheres e representação política: a experiência das cotas no Brasil. Estudos Feministas, Rio de Janeiro, v. 6, n. 1, 1998.

BITHIAH, Débora; RABAT, Márcio. Palavra de mulher: oito décadas de direito de voto. Brasília: Câmara dos Deputados, 2012. 
BUENO, Emma Roberta Palu; COSTA; Tailaine Cristina. Meu pé de cota laranja: a Justiça Eleitoral e o seu papel na garantia da efetivação da participação da mulher na política. In: Mulheres por mulheres: memórias do I Encontro de Pesquisa por/de/sobre Mulheres [recuso eletrônico] / Eneida Desiree Salgado; Letícia Regina Camargo Kreuz; Bárbara Mendonça Bertotti (Orgs.) - Porto Alegre, RS: Editora Fi, 2018.

BUONICORE, Augusto C. A república velha e os direitos das mulheres. In: NAZARIO, Diva Nolf. Voto Feminino e Feminismo. Diva Nolf Nazario. São Paulo: Imprensa Oficial do Estado de São Paulo, 2009.

BRASIL Anais do Congresso Constituinte de 1891. Disponível em: http:/ / bd.camara.leg.br/bd/handle/bdcamara $/ 2 /$ browse? value $=$ Processo+legislativo $\% 2 C+$ Brasil $\% 2 C+1891 \&$ type $=$ subjec. Acesso em: 05 abr. 2019.

CÂMARA DOS DEPUTADOS. Reserva de $\mathbf{3 0} \%$ de fundo de campanha para mulheres poderá alavancar candidaturas femininas. Disponível em: http://www2.camara.leg.br/camaranoticias/noticias/POLITICA/ 558950-RESERVA-DE-30-DE-FUNDO-DE-CAMPANHA-PARA-MULHERES-PODERA-ALAVANCAR-CANDIDATURAS-FEMININAS,-AVALIAM-DEBATEDORAS.html. Acesso em: 29 nov. 2018.

CÂMARA DOS DEPUTADOS. Bancada feminina na Câmara sobe de $\mathbf{5 1}$ para 77 deputadas. Disponível em: http://www2.camara.leg.br/camaranoticias/noticias/POLITICA/564035-BANCADA FEMININA-NA-CAMARA-SOBE-DE-51-PARA-77 DEPUTADAS.html. Acesso em: 28 nov. 2018.

CENTRO FEMINISTA DE ESTUDOS E ASSESSORIA - CFEMEA. Dados estatísticos das eleições de 2006 para Câmara dos Deputados, Senado Federal, Governos de Estado e Assembleias Legislativas. Disponível em: http://www.cfemea.org.br/index.php/eleicoes/eleicoes-anteriores/ eleicoes-2006/4702-dados-estatisticos-das-eleicoes-de-2006-para-camara-dos-deputados-senado-federal-governos-de-estado-e-assembleias-legislativas. Acesso em: 22 nov. 2018.

FREITAS, Juliana Rodrigues. O sistema de cotas de gênero e o óbice ao desenvolvimento no Brasil: reflexões iniciais acerca da reduzida participação feminina na política brasileira. In: PEREIRA, Rodolfo Viana; SANTANO, Ana Claudia (Orgs.). Conexões Eleitoralistas. Belo Horizonte: Abradep, 2016. GOMES, Jairo José. Direito Eleitoral. 13. ed. São Paulo: Atlas, 2017. MACHADO, Nélida Reis Caseca; LEAL, Noelly Antonia. O Lugar da Mulher é na Política? R. Curso Dir. UNIFOR-MG, Formiga, v. 6, n. 1, p. 1-11, jan./jun. 2015. 
MARTINI, Diandra Avila. Cotas partidárias e sub-representação feminina na América do Sul: um estudo comparado entre Brasil e Bolívia. Disponível em: https://www.ufrgs.br/sicp/wp-content/uploads/2015/09/DIANDRA-MARTINI.pdf. Acesso em: 20 abr. 2019.

MIGUEL, Sônia Malheiros. A política de cotas por sexo: um estudo das primeiras experiências no legislativo brasileiro. Brasília: CFEMEA, 2000.

OBSERVATÓRIO DE IGUALDADE DE GÊNERO DA AMÉRICA LATINA E DO CARIBE. Bolívia - Sistema político e eleitoral. Disponível em: https://oig.cepal.org/pt/paises/6/system. Acesso em: 20 abr. 2019.

PINHEIRO, Luana Simões. Vozes femininas na política: uma análise sobre mulheres parlamentares no pós-constituinte. Brasília: Secretaria Especial de Políticas para as Mulheres, 2007. (Série Documentos).

PINTO, Amanda Luiza Oliveira; BERTOT'TI, Barbara Mendonca; FERRAZ, Miriam Olivia Knopik. Reformas Legislativas de um Estado em Crise. 1.ed. Curitiba: Ithala, 2018.

PINTO, Celi Regina Jardim. Uma história do feminismo no Brasil. São Paulo: Perseu Abramo, 2003.

RANGEL, Patricia. (2012). Movimentos feministas e direitos políticos das mulheres: Argentina e Brasil. Tese de doutorado apresentada ao Ipol/UnB.

SALGADO, Eneida Desirre; GUIMARÃES, Guilherme A.; MONTE-ALTO, Eric Vinicius L. C. Cotas de gênero na política: entre a história, as urnas e o parlamento. Disponível em:http://periodicos.ufpb.br/ojs/index.php/ged/ article/view/25973. Acesso em: 18 abr. 2018.

SANCHEZ, Beatriz Rodrigues. Representação Política e gênero no Brasil e nos países de democratização recente. Revista de Iniciação Científica em Relações Internacionais, v. 1, n. 2, 2014.

SANTOS, Polianna Pereira dos. Participação da mulher na política - proposições e justificativas. Análise do quadro atual e proposições para a promoção do aumento da participação das mulheres na política. Parecer técnico, 2016.

; BARCELOS, Júlia Rocha de; PORCARO, Nicole Gondim. Participação da mulher na política: as reformas políticas que temos e as que queremos. In: PINTO, Amanda Luiza Oliveira; BERTOTTI, Barbara Mendonca; FERRAZ, Miriam Olivia Knopik. Reformas Legislativas De Um Estado Em Crise. 1. ed. Curitiba: Ithala, 2018. 
BARCELOS, Júlia Rocha de. Direitos Políticos das Mulheres e a regulamentação legal das cotas de gênero: resultados em Bolívia, Peru e Brasil. Anales de VIII Congresos Latinoamericanos de Ciencia Política ALACIP, 2015, v. I.

SANTOS, Tânia Maria dos. A Mulher nas Constituições Brasileiras. II Seminário Nacional de Ciência Política: América Latina em debate. - Porto Alegre, RS, 2009 .

SCHUMAHER, Schuma; BRASIL, Érico Vital: Dicionário mulheres do Brasil: de 1500 até a atualidade (biográfico e ilustrado). Rio de Janeiro: Zahar, 2000.

SENADO FEDERAL. Publicada lei que dá anistia e muda regra de prestação de contas de partidos. Disponível em: https:/ / www12.senado.leg. $\mathrm{br} /$ noticias/materias/2019/05/20/publicada-lei-que-da-anistia-e muda-regra-de-prestacao-de-contas-de-partidos. Acesso em 27 maio 2019.

SOUZA, Cristiane Aquino de. A Eficácia das Cotas Eleitorais da Argentina e no Brasil. Projeto de investigação "Democracia e Paridade de gênero", financiado pelo Conselho Nacional de Desenvolvimento Científico e Tecnológico $(\mathrm{CNPq})$ e pela Fundação Cearense de Apoio ao Desenvolvimento Científico e Tecnológico (FUNCAP), 2014.

TRIBUNAL REGIONAL ELEITORAL DO RIO GRANDE DO NORTE. Os 80 anos do voto de saias no Brasil. Disponível em: <http://www.tre-rn. jus.br/institucional/centro-de-memoria/os-80-anos-do-voto-de-saias-no-brasil-tre-rn>. Acesso em: 20 out. 2018.

TRIBUNAL SUPERIOR ELEITORAL. Registro de candidatura. Disponível em: http://www.tse.jus.br/o-tse/escola-judiciaria-eleitoral/publicacoes/ revistas-da eje/artigos/registro-de-candidatura. Acesso em: 10 nov. 2018.

TRIBUNAL SUPERIOR ELEITORAL - Acórdão em REspe n. 107079/ BA - PSS 11-12-2012. Disponível em http://www.tse.jus.br/jurisprudencia/ decisoes/jurisprudencia. Acesso em: 22 nov. 2018.

TRIBUNAL SUPERIOR ELEITORAL - Acórdão em REspe n. 2939/PE

- PSS 6-11-2012. Disponível em: http://www.tse.jus.br/jurisprudencia/decisoes/jurisprudencia. Acesso em: 22 nov. 2018.

TRIBUNAL SUPERIOR ELEITORAL. Fundo Eleitoral e tempo de rádio e TV devem reservar o mínimo de $30 \%$ para candidaturas femininas.

Disponível em: http://www.tse.jus.br/imprensa/noticias-tse/2018/Maio/fundo-eleitoral-e-tempo-de-radio-e-tv-devem-reservar-o-minimo-de-30-para-candidaturas-femininas-afirma-tse. Acesso em: 29 nov. 2018. 


\section{TRIBUNAL SUPERIOR ELEITORAL. Cruzamento de Dados por}

Gênero. Disponível em http://www.tse.jus.br/eleicoes/estatisticas/estatisticas-eleitorais. Acesso em: 22 nov. 2018.

TRIBUNAL SUPERIOR ELEITORAL. Mulheres representam 52\% do eleitorado brasileiro. Disponível em: http://www.tse.jus.br/imprensa/ noticias-tse/2018/Marco/mulheres-representam-52-do-eleitorado-brasileiro. Acesso em: 10 fev. 2019.

\section{TRIBUNAL SUPERIOR ELEITORAL. TSE finaliza julgamento das} contas partidárias de 2013. Disponível em: http://www.tse.jus.br/imprensa/ noticias-tse/2019/Abril/tse-finaliza-julgamento-das-contas-partidarias-de-2013. Acesso em: 28 maio 2019.

\section{TRIBUNAL SUPERIOR ELEITORAL: Número de mulheres eleitas} em 2018 cresce 52,6\% em relação a 2014. Disponível em: http://www.tse. jus.br/imprensa/noticias-tse/2019/Marco/numero-de-mulheres-eleitas-em-2018-cresce-52-6-em-relacao-a-2014. Acesso em: 10 jul. 2019.

VALENTE, Luiz Ismaelino; SALES, José Edvaldo Pereira. O Registro de Candidatos (artigos 10 ao 16-B). In: PINHEIRO, Célia Regina de Lima; FREITAS, Juliana Rodrigues. et. al. Comentários à Lei das Eleições. 1. ed. Belo Horizonte: Fórum, 2016.

VENTURINI, Anna Carolina; VILLELA, Renata Rocha. A inclusão de mulheres no parlamento como medida de justiça social: análise comparativa dos sistemas de cotas do Brasil e da Bolívia. Revista Eletrônica de Ciência Política, vol. 7, n. 1, 2016.

WOMEN IN NATIONAL PARLIAMENTS. Disponível em: http:/ /archive. ipu.org/wmn-e/classif.htm. Acesso em: 05 mar. 2019.

Crislayne Moura Leite - Graduanda do curso de Direito da Universidade Anhembi Morumbi. Estagiária no Escritório Rubens Naves Santos Júnior. E-mail: crislaynemouraleite@gmail.com.

Wagner Wilson Deiró Gundim - Doutorando em Filosofia do Direito pela Pontifícia Universidade Católica de São Paulo (PUC/SP). Bolsista CAPES na modalidade taxas. Mestre em Direito Político e Econômico pela Universidade Presbiteriana Mackenzie, tendo sido bolsista CAPES. Professor de Direito Constitucional, Ciência Política e Fundamentos do Direito Eleitoral na Universidade Anhembi Morumbi. Sócio Fundador do Gundim \& Advogados Associados. E-mail: wagner.gundim@adv.oabsp.org.br 
